\title{
Clinical Application of Angioscopy During Carotid Endarterectomy for Patients with Internal Carotid Artery Stenosis
}

\author{
Satoshi KurodA, Hiroyasu KAMIYAMA, Akihiro TAKAHASHI, \\ Kiyohiro HoUKIN, Hiroshi ABE and Hisatoshi SAITOH* \\ Department of Neurosurgery, Hokkaido University School of Medicine, Sapporo; \\ *Sapporo Azabu Neurosurgical Hospital, Sapporo
}

\begin{abstract}
The accuracy of angioscopy in detecting atherosclerotic changes, such as plaque, ulcer, and mural thrombus, in the extracranial cerebral arteries was evaluated during carotid endarterectomy by comparison with angiographic and operative findings. Ten patients with internal carotid artery stenosis underwent intraoperative angioscopy during surgery. After clamping the carotid bifurcation, intraarterial atherosclerotic lesions were observed with an angioscope $(0.8$ or $1.4 \mathrm{~mm}$ outer diameter) inserted through a small incision in the common carotid artery. Angioscopic findings correlated well with both angiographic and operative findings in six patients, and provided additional information in two patients, such as organized thrombi within the ulcer and mural thrombi. Angioscopic findings were quite different to those from angiograms in two patients. In one, an ulcer on angiograms was false positive, and in the other, false negative. These findings were confirmed intraoperatively. Our results suggest that preoperative carotid angioscopy is of great value in detecting ulcers more accurately than angiography, and in selecting candidates for carotid endarterectomy, although further development of equipment is needed.
\end{abstract}

Key words: angiography, angioscopy, internal carotid artery, carotid endarterectomy, ulcer

\section{Introduction}

Angioscopy has recently entered use in the field of neurosurgery. Further development of this technique will allow direct visualization (via the vascular lumen) of atheroma and ulceration in the extracranial major cerebral arteries and safer angioplasty using a balloon and/or laser.

At present, however, angioscopic observation of atherosclerotic lesions at the origin of the internal carotid artery is limited by blood flow obliteration, the necessity of eliminating blood in the operative field, and the limited duration. Optimum technical procedures, accuracy, and safety of preoperative percutaneous angioscopy are not yet established.

This study assessed the accuracy of angioscopic visualization of atherosclerotic lesions during carotid endarterectomy (CEA) compared with angiographic and intraoperative findings.

Received January 11, 1993;

Accepted May 10, 1993

\section{Clinical Materials and Methods}

This study included 10 males who developed transient ischemic attack (TIA), reversible ischemic neurological deficit, or minor completed stroke.

An Olympus angioscope PF type 14 (outer diameter $1.4 \mathrm{~mm}$, effective length $1200 \mathrm{~mm}$ ) was used in eight cases, and an Olympus angioscope XPF type $8(0.8 \mathrm{~mm}, 400 \mathrm{~mm})$ in two cases (Olympus Corp., Tokyo).

All patients underwent CEA using a conventional approach. After exposure of the common carotid artery bifurcation, the common carotid, the internal carotid, the external carotid, and the superior thyroid arteries were occluded. A small incision was made in the common carotid artery, and an introducer with a diameter of 5 or 7 French (depending on the outer diameter of the angioscope) was inserted distally. The arterial lumen was filled with heparinized saline. The angioscope was then inserted through the introducer to observe the intra-arterial le- 
sions. Angioscopic findings were recorded on video tapes. The common carotid and the internal carotid arteries were further incised, and endarterectomy performed using microsurgical techniques. When the arteriotomy closure was almost complete, the angioscope was inserted again through the residual arteriotomy wound. The lumen was filled with heparinized saline and the operated area again observed.

Intraoperative monitoring of the electroencephalograms or somatosensory evoked potentials was performed in all patients.

\section{Results}

Observation of the carotid artery lumen was possible in all patients (Table 1).

In Patients 1-6, the features suggested by cerebral angiograms were identified by the angioscopy and intraoperative findings. In Patients $1-3$, plaque with a smooth or irregular surface suggested by cerebral angiograms agreed with the angioscopic findings of stenosis of the internal carotid artery lumen due to plaque (Fig. 1). In Patients 4-6, the ulceration suggested by cerebral angiograms was also observed by intraoperative angioscopy (Fig. 2).

In Patients 7 and 8, angioscopy provided additional information to the findings of cerebral angiography. In Patient 7, angioscopy disclosed organized thrombi within the ulcer, while the angiograms demonstrated only intra-plaque ulcer. In Patient 8, cerebral angiograms suggested severe stenosis at the origin of the internal carotid artery caused by plaque, but intraoperative angioscopy

Table 1 Summary of results

\begin{tabular}{|c|c|c|c|c|}
\hline $\begin{array}{l}\text { Patient } \\
\text { No. }\end{array}$ & $\begin{array}{l}\text { Age/ } \\
\text { Sex }\end{array}$ & $\begin{array}{l}\text { Diag- } \\
\text { nosis }\end{array}$ & Angiography & $\begin{array}{c}\text { Endoscopy and } \\
\text { operation }\end{array}$ \\
\hline 1 & $63 / \mathrm{M}$ & RIND & smooth plaque & smooth plaque \\
\hline 2 & $65 / \mathrm{M}$ & TIA & $\begin{array}{l}\text { irregular } \\
\text { plaque }\end{array}$ & irregular plaque \\
\hline 3 & $59 / \mathrm{M}$ & RIND & $\begin{array}{l}\text { irregular } \\
\text { plaque }\end{array}$ & irregular plaque \\
\hline 4 & $59 / \mathrm{M}$ & TIA & ulcer & ulcer \\
\hline 5 & $60 / \mathrm{M}$ & MiCS & ulcer & ulcer \\
\hline 6 & $70 / \mathrm{M}$ & MiCS & ulcer & two ulcers \\
\hline 7 & $57 / \mathrm{M}$ & $\mathrm{MiCS}$ & ulcer & $\begin{array}{l}\text { organized thrombus } \\
\text { in ulcer }\end{array}$ \\
\hline 8 & $60 / \mathrm{M}$ & $\mathrm{MiCS}$ & $\begin{array}{c}\text { plaque (severe } \\
\text { stenosis) }\end{array}$ & mural thrombus \\
\hline 9 & $63 / \mathrm{M}$ & MiCS & plaque & ulcer in plaque \\
\hline 10 & $59 / \mathrm{M}$ & TIA & ulcer & smooth plaque \\
\hline
\end{tabular}

MiCS: minor completed stroke, RIND: reversible ischemic neurological deficit, TIA: transient ischemic attack.

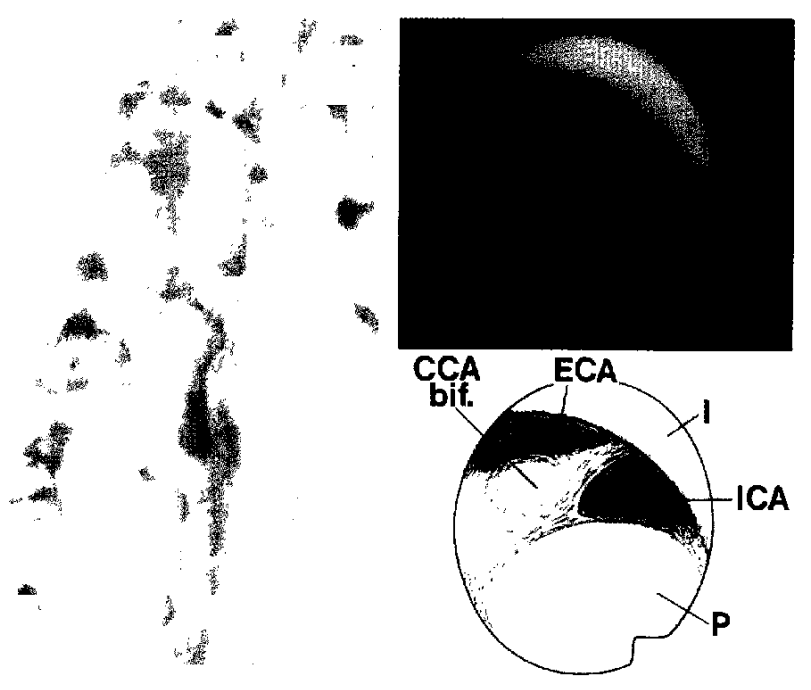

Fig. 1 Patient 1, a 63-year-old male with mild left hemiparesis lasting for about 2 weeks. left: Right carotid angiogram, demonstrating a well-defined filling defect with sharp margins, suggesting a smooth-surface plaque. right: Intraoperative carotid angioscopic image, revealing smooth-surface plaque $(P)$ at the origin of the internal carotid artery (ICA), well correlated with the angiographic finding. CCA bif.: common carotid artery bifurcation, ECA: external carotid artery, I: introducer.

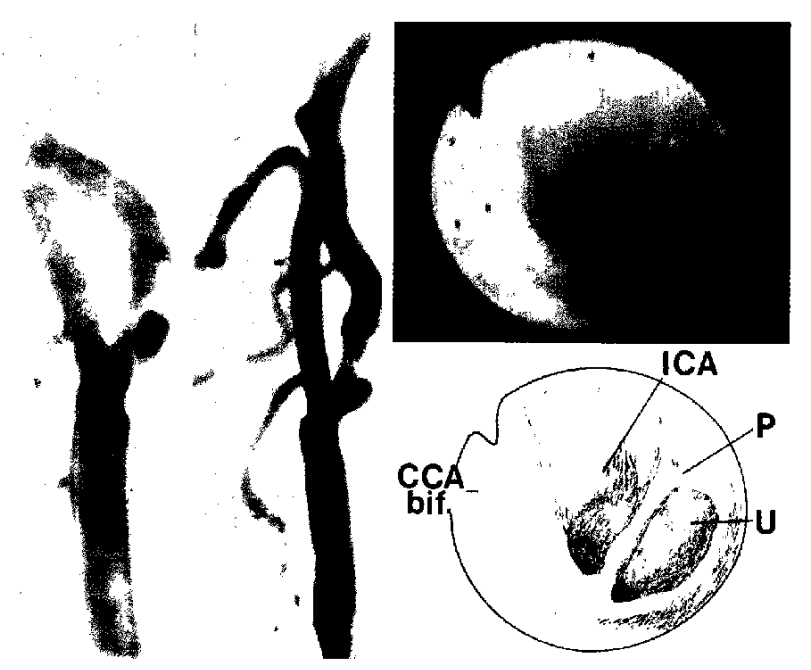

Fig. 2 Patient 6, a 70-year-old male with mild right hemiparesis. left: Left carotid angiograms, showing a central collection of contrast material with a filling defect, suggesting an ulcerative plaque. right: Carotid angioscopic image, disclosing a typical ulcer formation (U) at the origin of the internal carotid artery (ICA). CCA bif.: common carotid artery bifurcation, P: plaque. 

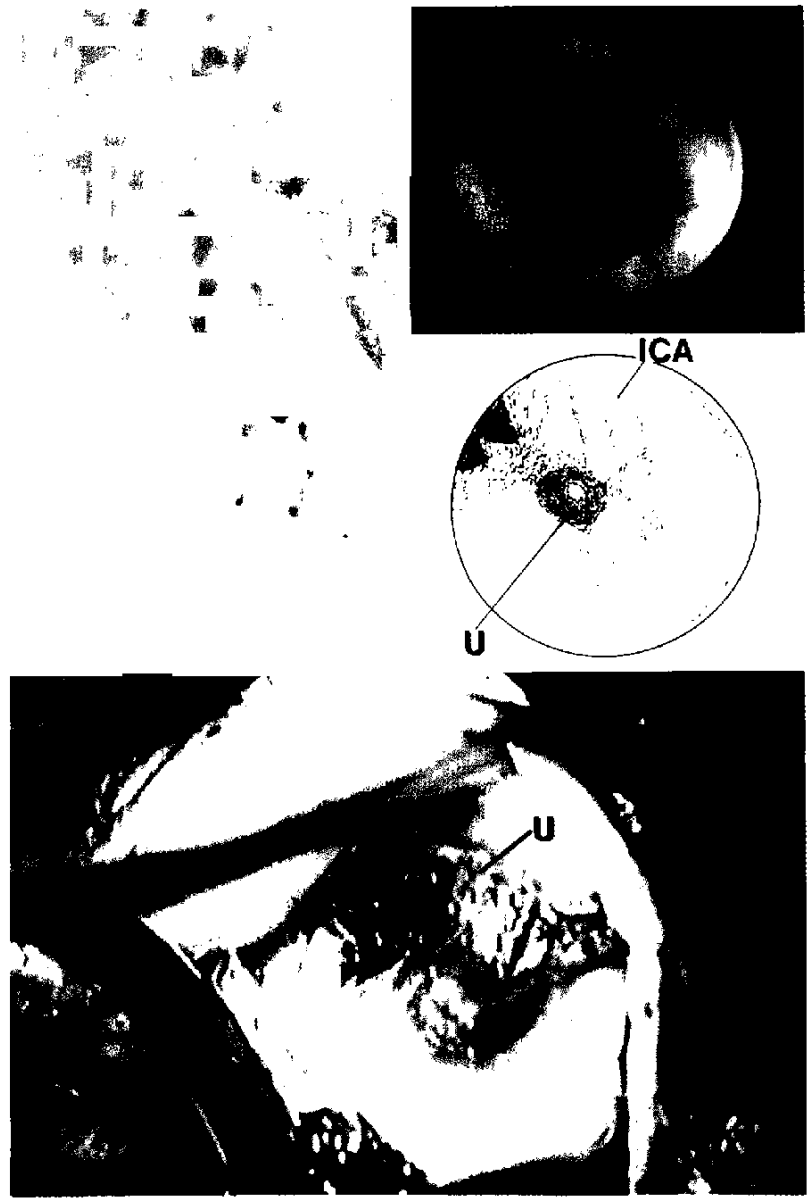

Fig. 3 Patient 9, a 63-year-old male with recurrent left hemiparesis. upper left: Right carotid angiogram, showing stenosis of the internal carotid artery caused by plaque with a slightly irregular surface. upper right: Carotid angioscopic image, revealing ulcer formation (U) at the origin of the internal carotid artery (ICA). lower: Intraoperative observation, demonstrating an ulcer crater in the wall of the artery. CCA: common carotid artery.

revealed that the lumen was almost completely filled with mural thrombi adhered to the plaque. These findings were confirmed during operation.

In Patients 9 and 10, the angioscopic findings differed from the angiographic findings. In Patient 9 with minor completed stroke, preoperative cerebral angiograms suggested stenosis of the internal carotid artery caused by plaque with a slightly irregular surface, while intraoperative angioscopy revealed ulcer formation within the plaque (Fig. 3). In Patient 10 with TIA, preoperative angiograms disclosed central accumulation of contrast material with well-marginated smooth plaque, suggesting

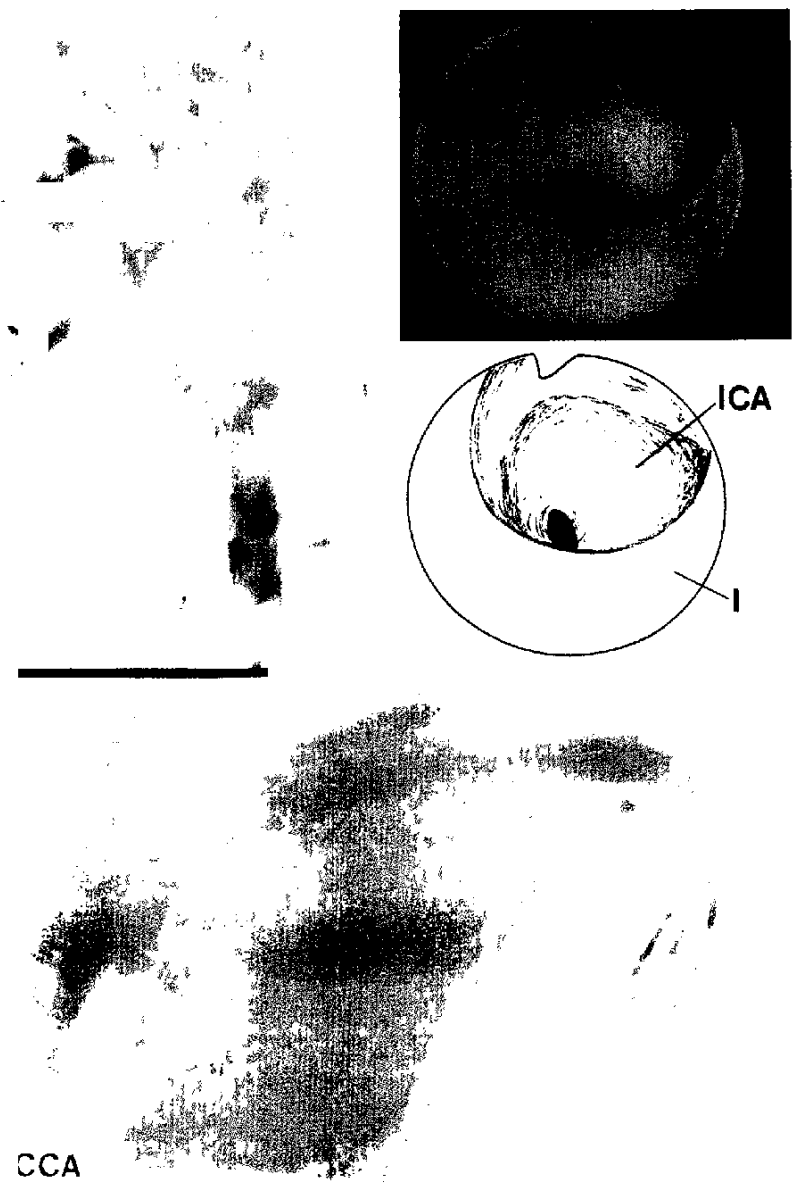

Fig. 4 Patient 10, a 59-year-old male with transient right hemiparesis, upper left: Left carotid angiogram, showing a central collection of contrast material, strongly suggesting ulcer formation. upper right: Intraoperative carotid angioscopic image, revealing plaque with a central depression covered by an intact intima. I: introducer, ICA: internal carotid artery. lower: Intraoperative observation, disclosing findings supporting the angioscopic image. CCA: common carotid artery, ECA: external carotid artery.

a typical ulcer at the origin of the internal carotid artery, but angioscopy revealed plaque with a central depression covered by an intact intima (Fig. 4). These angioscopic findings were confirmed during surgery.

The endarterectomized surface of the carotid artery revealed numerous minute feather-like strands floating in the saline. These fragments were too small to be grasped and removed even under a microscope, and so were left in situ.

Intraoperative angioscopy caused no complica- 
tions. In all cases, the time from carotid clamping to reperfusion with an internal shunt tube was 5 minutes or less. No recurrent stenosis or occlusion of the internal carotid artery was observed postoperatively.

\section{Discussion}

Studies of the mechanisms by which cerebral ischemia is induced by atherosclerotic lesions at the origin of the internal carotid artery have identified the degree of stenosis (i.e. plaque size), ulceration, and histology of plaque as important factors. ${ }^{7,19}$ More recently, intraplaque hemorrhage ${ }^{3,10)}$ and plaque disruption ${ }^{6)}$ have been considered important in the induction of cerebral ischemia.

Cerebral angiography was previously the most reliable method for observing atherosclerotic lesions of the carotid artery. However, accurate diagnosis of lesions cannot always be achieved with angiography alone. The degree of stenosis tends to be underestimated, and false-positive or false-negative diagnosis of ulcers is higher than previously thought..$^{2,4,5,16-18)}$ B-mode ultrasonography can detect ulcers and plaque more sensitively than cerebral angiography, but the diagnostic accuracy is sometimes lower than that of angiography.

Angioscopy, which has a long history in the cardiovascular field, has recently been introduced in neurosurgery. Olinger ${ }^{15)}$ observed the internal carotid artery lumen using angioscopy in autopsy cases and suggested that this modality could detect fatty dots, gelatinous plaques, mural thrombi, thrombosis, and ulcers with or without organizing thrombi. Mehigan ${ }^{12)}$ inserted an angioscope into the carotid artery at the end of CEA, and observed the endarterectomized surface and the operative stumps. The features of the freed surface in this study were similar to those found in the present study. Percutaneous angioscopy is also used for observation of the extracranial vertebral and carotid arteries. ${ }^{9,133}$

In our study, the features suggested by cerebral angiography were supported by angioscopy in Patients 1-6. In Patients 7 and 8, angioscopy provided information additional to the angiographic findings. In Patients 9 and 10, angioscopy allowed accurate diagnosis of ulcers which were false negative or false positive by angiography.

This intraoperative study was intended to assess how accurately angioscopy can demonstrate atherosclerotic changes in the carotid artery. Our angioscopic findings were obtained under optimal conditions where blood flow was obstructed and the vascular lumen was filled with heparinized saline dur- ing surgery. Similar information obtained by preoperative percutaneous angioscopy would have been most valuable in studying the mechanism inducing cerebral ischemia and in selecting patients for CEA, especially when angioscopy revealed organized thrombi within ulcers (Patient 7), or the presence or absence of ulcers (Patients 9 and 10).

Despite these advantages, preoperative percutaneous angioscopy has not been widely used, probably because of problems such as: i) temporary ischemia due to obstruction of carotid artery flow, ii) required elimination of blood in the visual field, and iii) limited duration of observation due to back flow. ${ }^{9,13)}$ Furthermore, we found difficulty in accurately assessing the degree of plaque-caused stenosis with angioscopy. However, further development of equipment and technique may solve these problems in the near future.

Perioperative complications and long-term prognosis require more careful assessment of indications for CEA. ${ }^{1,8,9,11,14)}$ Preoperative angioscopy is potentially important in selecting candidates for CEA, especially in identifying patients with ulceration and mural thrombus of the carotid artery.

\section{Acknowledgments}

We would like to thank Drs. Mitsuyuki Koiwa and Takeshi Kashiwaba, Kashiwaba Neurosurgical Hospital, Sapporo, and Drs. Tango Nakagawa and Kenji Mitsumori, Hokkaido Neurosurgical Memorial Hospital, Sapporo for referring the patients included in this study.

\section{References}

1) Bogousslavsky J, Despland PA, Regli F: Prognosis of high risk patients with nonoperated symptomatic extracranial carotid tight stenosis. Stroke 19: 108111,1988

2) Croft RJ, Ellam LD, Harrison NJG: Accuracy of carotid angiography in the assessment of the internal carotid artery. Lancet 1: 997-999, 1980

3) Edwards JH, Kricheff II, Gorstein F, Riles T, Imparato AM: Atherosclerotic subintimal hematoma of the carotid artery. Radiology 133: 123-129, 1979

4) Edwards $\mathbf{J H}$, Kricheff II, Riles T, Imparato AM: Angiographically undetected ulceration of the carotid bifurcation as a cause of embolic stroke. Radiology 132: 369-373, 1979

5) Eikelboom BC, Riles TR, Mintzer R, Baumann FG, DeFillip C, Lin J, Imparato AM: Inaccuracy of angiography in the diagnosis of carotid ulceration. Stroke 14: 882-885, 1983

6) Fisher M, Blumenfeld AM, Smith TW: The impor- 
tance of carotid artery plaque disruption and hemorrhage. Arch Neurol 44: 1086-1089, 1987

7) Gomez CR: Carotid plaque morphology and risk for stroke. Stroke 21: 148-151, 1990

8) Krul JMJ, van Gijin J, Ackerstaff RGA, Eikelboom BC, Theodorides T, Vermeulen FEE: Site and pathogenesis of infarcts associated with carotid endarterectomy. Stroke 20: 324-328, 1989

9) Kuroda S, Yonekawa Y, Kawano K, Yamashita K, Taki W: Clinical application of intravascular endoscopy for patients with occlusive carotid disease, in: Proceedings of the 5th Workshop on Intravascular Surgery. 1991, pp 279-283 (in Japanese)

10) Lusby RJ, Ferrell LD, Eherenfeld WK: Carotid plaque hemorrhage: Its role in production of cerebral ischemia. Arch Surg 117: 1479-1488, 1982

11) Lusby RJ, Wylie EJ: Complication of carotid endarterectomy. Surg Clin North Am 63: 1293-1302, 1983

12) Mehigan TJ: Carotid angioscopy, in: Angioscopy; Vascular and Coronary Applications. Chicago, Year Book Medical Publishers, 1989, pp 84-88

13) Miyamoto $S$, Kikuchi $H$, Nagata $I$, Yamagata $S$, Kaneko T, Akiyama Y, Ito K, Kim SH, Mitsuno K: The application of vascular endoscope for the extracranial cerebrovascular occlusive disease: The development of the endoscopic system. No Shinkei Geka 17: 625-628, 1989 (in Japanese)
14) O'Holleran LW, Kennelly MM, McClurken M, Johnson JM: Natural history of asymptomatic carotid plaque. Five-year follow-up study. Am J Surg 154: 659-662, 1987

15) Olinger CP: Carotid artery endoscopy (autopsy). Surg Neurol 7: 7-13, 1977

16) Ricotta JJ, Bryan FA, Bond MG, Kurtz A, O'Leary DH, Raines JK, Berson AS, Clouse ME, CalderonOritz M, Toole JF, DeWeese JA, Smullens SN, Gustafson NF: Multicenter validation study of realtime (B-mode) ultrasound, arteriography, and pathologic examination. J Vasc Surg 6: 512-520, 1987

17) Ricotta JJ, Schenk EA, Ekholm SE, DeWeese JA: Angiographic and pathologic correlates in carotid artery disease. Surgery 99: 284-292, 1986

18) Senkowsky J, Bell WH, Kerstein MD: Normal angiograms and carotid pathology. Am Surg 56: 726729,1990

19) Wechsier LR: Ulceration and carotid artery disease. Stroke 19: 650-653, 1988

Address reprint requests to: S. Kuroda, M.D., Department of Neurosurgery, Hokkaido University School of Medicine, North-15, West-7, Kita-ku, Sapporo 060, Japan. 